\title{
NARRADOR Y NARRATARIO EN EL CINE DOCUMENTAL TRANSMEDIA ${ }^{1}$
}

\author{
Mario de la TORRE-ESPINOSA \\ Escuela Universitaria TAI (Universidad Rey Juan Carlos) \\ Centro Universitario San Isidoro (Universidad Pablo de Olavide) \\ mario.delatorre@escuela-tai.com
}

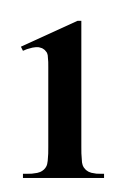

\section{Introducción: narratología transmedia y cine}

Hablar de narrador y de narratario haciendo referencia al cine constituye un verdadero reto por la dificultad de la traslación de ciertos conceptos teóricos de la literatura al ámbito audiovisual. Aun así, negar la posibilidad de emplear estas nociones en el séptimo arte supone una traición a sus propias posibilidades, y es por ello que desde el ámbito de la literatura comparada se haya visto como legítimo llevar a cabo esta transferencia a pesar de las reticencias de algunos investigadores de la literatura para quien constituye una heterodoxia inasumible, así como parte notable de los especialistas en estudios fílmicos que ven una intromisión injustificada en su campo, sobre todo por el miedo a que la teoría del cine sea colonizada por concepciones previas y ajenas que no consideran viables. Pero si algo define a la teoría es su capacidad de articularse en diferentes ámbitos de la realidad sociosemiótica, mostrando su maleabilidad siempre que se lleve a cabo con todo el rigor y la coherencia posibles.

Partimos así de la idea de que los diferentes modos y tipos narrativos tienen cierta autonomía respecto al tipo de técnica con el cual se desarrolle o bien del lenguaje artístico con el que se articule, aunque dependiendo de cada medio se deberán matizar estos conceptos y sus aplicaciones. Y a este respecto las narrativas transmediales se han constituido en un buen ejemplo de cómo en la contemporaneidad se puede hablar de modelos narrativos — aunque también se puede enfocar desde el estudio de los medios - independientemente de la plataforma en la que se materialice, como se puede ver en la aplicación de la narratología sobre lo transmedia efectuada por Marie-Laure Ryan $(2014,2016)$. Tanto es así que incluso podríamos decir que dicho modelo transmedial es el resultante de la conjunción de varias narrativas que convergen en un relato unificador, y donde el espectador/ lector/usuario se constituye en elemento configurador clave de la experiencia final al decidir el grado de inmersión que desea.

\footnotetext{
1 Este artículo se enmarca dentro del proyecto Narrativas transmediales: nuevos modos de ficción audiovisual, comunicación periodística y performance en la era digital (Referencia CSO2013-47288-P), dirigido por el profesor Domingo Sánchez-Mesa Martínez. Ministerio de Economía y Competitividad.
} 
Ya Francis Vanoye (1998), André Gaudrealt y François Jost (2001) asumieron estos preceptos para dar forma a la narratología fílmica. Siguiendo los trabajos de Gérard Genette o Tzvetan Todorov, lograron dar desarrollo a términos surgidos de lo literario y aplicarlos en el ámbito cinematográfico. A este respecto es básica la figura del narrador, ya que el cine, al ser un medio audiovisual, lleva asociadas otras cuestiones que requieren de consideraciones varias. Entre ellas la habitual invisibilidad del autor en el cine convencional, práctica proveniente del modelo del cine clásico ${ }^{2}$, una de cuyas marcas rectoras es la transparencia de la instancia enunciadora. Esto provoca que el narrador quede «fuera de campo», aunque el cine ha sabido desarrollar estrategias para dejar bien claro que sí existe una figura narradora.

De lo que no cabe duda es que el discurso cinematográfico, y siguiendo la idea de la gran sintagmática de Christian Metz, está formado por una serie de enunciados que remiten al enunciador como sujeto que activa la narración — aunque puede existir enunciados que no constituyan narraciones per se- Lo difícil sería determinar con quién se corresponde esa figura en el cine, cuando existe un código visual y otro sonoro que configura la naturaleza audiovisual del séptimo arte. Dejamos claro que no pretendemos asimilar autor con narrador, aunque en el caso del cine documental podemos encontrar ejemplos de narración autodiegética que desdicen esto (Torre Espinosa, 2015). Pero es importante romper con la aparente inocencia espectatorial heredera de las prácticas cinematográficas del periodo clásico.

Si estamos ante las primeras películas de los hermanos Lumière, la invisibilidad enunciativa nos puede hacer creer que las imágenes son tomadas de forma espontánea y sin la intervención de ningún sujeto narrativo. Pero esto no deja de ser una falacia sobre la que se han edificado algunas teorizaciones sobre el cine, porque en realidad siempre existe una mirada que decide los elementos que van a ser filmados. Otra cuestión es si dicha visión se corresponde con un autor único o si se trata de una autoría colectiva. Si pensamos en el primer caso, es imposible de aplicar al cine la categoría de autor en su consideración tradicional dada la cantidad de personas que intervienen habitualmente durante todo el proceso creativo, pero esto no quita que haya una clara intencionalidad creadora en la configuración del relato final. Existe además la posibilidad de considerar una instancia narradora implícita en el relato cinematográfico que nos permita realizar una lectura narratológica del cine, idea a la que Gaudreaul y Jost darían forma bajo la denominación del Gran Imaginador (2001), que evidencia un sujeto enunciador a través de ciertos deícticos, como pueden ser determinados elementos de la puesta en escena como decorados, ciertas planificaciones o bien ritmos de montaje. Si pensamos en el cine de directores como Quentin Tarantino o Pedro Almodóvar podemos ver claramente cómo estas marcas estilísticas evidencian a ese Gran Imaginador. Dejan de ser imágenes «espontáneas» para configurarse en marcas de autoría que remiten a una instancia narradora. Esto sería precisamente lo que desde Cahiers du Cinéma y sus epígonos se tomaría como base para el desarrollo de la politique des auteurs, donde defenderían la presencia de esas señales identificables, en filmes en principio comerciales y

\footnotetext{
${ }^{2}$ A este respecto es básico remitirnos a Nöel Burch (1999), quien dio forma a esta forma cinematográfica como Modo de Representación Institucional.
} 
destinados a un gran público, como indicios de la presencia de un autor, que al mismo tiempo podría incluso ejercer de narrador heterodiegético implícito.

Otra cuestión sería la del narratario, ese destinatario al cual se dirige el relato cinematográfico. Evidentemente, y de nuevo, no queremos asimilar una figura del mundo real - lector o espectadorcon una de un universo ficticio - narratario-, pero es importante recordar que dentro de las narrativas transmedia se produce una interpelación directa al usuario de forma que se propicie su participación activa en el proceso lúdico-creativo, y al mismo tiempo que con dicha interacción se contribuya a la expansión del universo ficcional generado.

Habitualmente el cine mainstream muestra seria resistencia a este respecto al proceder a la uniformización de los espectadores. Se crean obras buscando el mayor poder expresivo y al mismo tiempo lograr una gran persuasión con la estructuración del relato, ya que cuyo objetivo es lograr la mayor recaudación posible. Pero con la irrupción de los estudios feministas, poscoloniales o queer estas estrategias serían puestas en evidencia revelando la necesidad de que el espectador deje de formar parte de una masa acrítica. El relato se convertirá así en una herramienta de interpelación directa al revelar en su estatuto espectatorial al público y al develar las ideas políticas desarrolladas en estos filmes.

Siguiendo con el cine en su vertiente industrial, su rendimiento económico ha sido potenciado con estrategias como la segmentación de audiencias. Los productores han logrado así generar productos audiovisuales destinados a públicos concretos y, más aún, han conseguido que un mismo producto tenga diferentes versiones adaptándose a las presuntas necesidades específicas de cada uno de los targets a los cuales se destinan esas obras. Por lo tanto, el conocimiento real sobre las posibilidades narrativas de cada medio ha favorecido que las propuestas llevadas a cabo sean exitosas, sobre todo porque estas se han sabido orientar a un tipo de usuario determinado. El crossmedia se podría entender como un fenómeno resultante de estas prácticas comerciales, como se puede observar en el muy citado caso de la saga Star Wars y todos los productos derivados de esta saga fílmica, como puede el merchandising destinado a un público infantil.

Pero al hablar de transmedialidad estamos haciendo referencia, entre otras cosas, a una diversidad de plataformas y medios sobre los que se desarrollará un relato. El hecho de que al diseñar una estrategia transmedial para un producto audiovisual se tenga en cuenta a qué sectores de la audiencia va destinado cada elemento puede llevar a una consecución más directa de objetivos como el engagement ${ }^{3}$. Y a este respecto la explicitación en la narración del narratario, y la coincidencia de esta figura con la del espectador, puede hacer que la experiencia tenga un alto potencial persuasivo y así el mensaje de las obras llegue lo más lejos posible.

Por tanto, narrador y narratario en el cine se constituyen en dos términos de controvertida y compleja aplicabilidad, pero que sin lugar a dudas abre las puertas a reconsideraciones en torno a las prácticas audiovisuales, tanto tradicionales como transmedia. Desde este trabajo vamos a analizar

\footnotetext{
${ }^{3}$ Con el término engagement entendemos el resultado de vincular a un usuario con un producto transmedia, de manera que se convierta en un agente de expansión de dicho universo transmedial al convertirse en un fan.
} 
cómo ciertos autores han sido conscientes de todo este potencial y han creado así propuestas donde, dependiendo de la plataforma escogida, estas entidades narrativas han ido variando mediante estrategias diversas y buscando la concienciación social.

\section{Consideraciones generales en torno al documental transmedia}

Resulta complejo asumir una definición canónica de cine documental en nuestros días. La variedad de tipos y la hibridación en sus formas hace que este género cinematográfico rehúya encuadrarse incluso como estilo, apareciendo categorías como no ficción o documental expandido para intentar crear un cajón de sastre donde introducir propuestas de diversa índole. ¿Pero dónde reside pues la clave para catalogar un trabajo audiovisual dentro de la categoría «documental»? Como punto de partida podríamos remitirnos a Bill Nichols: «Las películas documentales hablan acerca de situaciones o eventos reales, y respetan los hechos conocidos; no introducen hechos nuevos e inverificables. Hablan directamente, más que de manera alegórica, sobre el mundo histórico» (2013: 27). Estas palabras, a pesar de excluir algunas nuevas formas de documental, nos son de especial importancia por la referencia que hace al mundo histórico. Sin lugar a dudas el género documental recoge momentos históricos concretos, pero no sólo hechos acaecidos en una época determinada, ya que también durante la enunciación se fija la obra a un marco sociohistórico único. Como consecuencia, para que la experiencia espectatorial sea intensa, debe existir coherencia plena en ese mundo histórico recreado - no inventado - y su narración, de forma que le sea posible su contraste con el mundo real.

Sin lugar a dudas aquí reside una de las principales tensiones que se pueden generar al intentar hablar de transmedialidad y cine documental, y es la idea de mundo transmedia. Sin lugar a dudas constituye un punto de referencia esencial, puesto que desde las teorizaciones más tempranas a este respecto, y tal y como apuntó Nieves Rosendo, «se observa la centralidad del concepto de mundo en las narrativas transmediales» (2016: 51). Tomemos como muestra la siguiente definición de Henry Jenkins: «Transmedia storytelling represents a process where integral elements of fiction get dispersed systematically across multiple delivery channels for the purpose of creating a unified and coordinated entertainment experience» (Jenkins, 2007). En esta definición podemos ver cómo lo ficcional se constituye en elemento esencial dentro de la experiencia transmedial, excluyendo, y siendo rigurosos respecto a la idea de Jenkins, al género documental. Esta idea estaría conectada también con su noción de making worlds, para él consustancial a la naturaleza de los productos transmedia. Mientras tanto, en el género documental se trataría más bien de reflecting worlds, ya sea a través de una mera mediación creativa — siguiendo la tradicional definición de John Grierson-, ya sea mediante diversas estrategias expresivas que alejen al documental de la clásica modalidad expositiva.

Habría que recordar que Star Wars o Juego de Tronos no dejan de tener su base en el mundo factual, puesto que los comportamientos que aparecen y las emociones que se reflejan son reconocibles en cualquier ciudadano; lo que les diferencia es que el momento histórico o los personajes que aparecen no son humanos, correspondiéndose así con mundos fantásticos. Pero en el documental esto es invia- 
ble, puesto que es básico que exista una conexión máxima con lo real, ya que esto será lo que le dote de verdadero poder persuasivo. Y además, debe existir coherencia entre lo representado y el mundo real, puesto que cualquier disonancia puede hacer al espectador desconfiar de lo narrado como verdadero. Estaría en conexión con la idea de verosimilitud, para Christian Metz una cuestión de reiteración del discurso sobre el que se edifica un tipo de cine determinado, en el cual se «actualiza o reactualiza uno de esos posibles que están en la vida (si se trata de una obra "realista") o en la imaginación de los hombres (si se trata de una obra "fantástica" o "no realista")» (1970: 25). Evidentemente el cine documental estaría en sintonía con la primera parte de la definición, ya que se trataría siempre del retrato de uno de esos «posibles» a los que hace mención Metz.

Una de las características de los mundos transmediales ficcionales, a los que ya hemos hecho mención, es que deben tener coherencia interna. Al hablar de transmedia, y al migrar la historia o personajes entre diferentes medios, debe permanecer esa unidad independientemente de la plataforma seleccionada o el lenguaje empleado. Esto contribuirá a que la experiencia no sea frustrante para aquellos usuarios que hayan decidido introducirse en un mundo determinado y hayan encontrado incompatibilidades en el mismo. ¿Pero qué sucede con los documentales transmedia, donde no se da una pluralidad de mundos imaginarios, puesto que lo que se pretende reflejar son realidades de un único mundo real y verificable? En el documental, para suscitar el interés del público, es preciso que se relaten partes de la realidad que se desconocen, que se conocen de forma incompleta, o al menos de manera distinta a la que los medios de comunicación nos tienen acostumbrados. Se trataría por tanto, más que del conocimiento de nuevos mundos, del acercamiento al espectador de realidades presentes en el mundo real para, y desde ahí, configurarse la experiencia narrativa ${ }^{4}$. Se constituye así como una herramienta fenomenológica que se apodera de las ventajas de los diferentes media para hacer la experiencia lo más enriquecedora posible ${ }^{5}$.

En esta confrontación entre mundos ficcionales y documentales transmedia nos sumamos a la visión de Marie-Laure Ryan (2014), quien desde la narratología ofrece la posibilidad de extender lo transmedia a narraciones factuales. Se trata, pues, de excluir la ficción como condición sine qua non para que se dé lo transmedia, ampliando de esta forma sus posibilidades expresivas ${ }^{6}$. Y no es baladí esta cuestión porque este asunto tiene ahora una vigencia vital, puesto que en la «pasión de lo real» que caracteriza nuestros tiempos, y tal como lo define Slovaj Žižek (2005), dicha categoría de realidad tiene una nueva consideración ontológica producto de la deriva del capitalismo, y cuyas fronteras son cada vez más frágiles. El género documental, como producto que responde a la realidad en que se

\footnotetext{
${ }^{4}$ Es importante resaltar cómo esta nueva deriva transmedial del género documental provoca un cambio en los sistemas de producción cinematográficos tradicionales: «Ahora esto es el desafío enfrentado por el productor de documentales: juntar en un único plot narrativo, además de diversas posibilidades narrativas, innúmeras historias de realidad, independientes entre sí, por plataformas distintas (geográficas o de lenguaje, como defiende Jenkins) y producidas también por y para dispositivos móviles» (Renó, 2014: 2).

${ }^{5}$ Como consecuencia de esto se pueden contemplar fenómenos como el crowdsourcing, en este caso cuando los usuarios van añadiendo piezas audiovisuales al proyecto documental transmedia, lográndose así una visión más completa del mundo factual que está siendo retratado.

${ }^{6}$ Marie-Laure Ryan se convierte en una gran referencia a la hora de defender que lo transmedia pueda tener su base en lo factual, siendo esto igualmente legítimo que su aplicación a partir de mundos ficcionales: «I find transmedia to be a very appropriate mode of presentation for non-fictional projects» (2016: 2).
} 
produce, se halla inmerso de lleno en esta dinámica, hasta el punto que es difícil discernir el grado de factualidad necesario para que se den obras audiovisuales de esta índole. Sobre todo porque cada vez estamos asistiendo a una mayor ficcionalización de la realidad. Se trata de una estrategia creativa, puesto que, y tomando prestadas las palabras de Paul Ricoeur, «gracias a su mayor libertad respecto a los acontecimientos realmente ocurridos en el pasado, la ficción despliega, respecto a la temporalidad, recursos de investigación prohibidos al historiador» (1987: 372). Si el documental retrata un momento histórico determinado, gracias a la ficcionalización de la experiencia se puede alcanzar nuevas cotas expresivas y por tanto, al hablar de transmedialidad, favorecer la creación de diferentes narraciones en diferentes medios que incluso lleven asociados objetivos particulares.

A este cambio de paradigma en el documental contemporáneo, con la expansión del documental hacia otras formas nuevas, hay que sumarle el hecho de que la propia definición de transmedia conlleva el desarrollo de diferentes formatos en diferentes medios. Dependiendo de la propia naturaleza de los mismos, la ficción se hace más o menos presente, puesto que hay formatos más favorables a la generación de contenidos ficcionales que otros. O que incluso, en la búsqueda del mayor engagement posible, se usen recursos ficcionales para dar a esos fragmentos de realidad una mayor eficacia persuasiva. A esto hay que sumar la aparición de desarrollos tecnológicos que han hecho que el documental adquiera nuevas formas, potenciándose así la experimentación con la narración como consecuencia de la invención de nuevos dispositivos.

Esto genera también una interesante controversia en cuanto a la posibilidad de hablar de documentales transmedia puros. Sobre todo porque si bien la presencia de un documental puede ser un elemento clave en la narración transmedia, la propia naturaleza centrífuga de lo transmedial lleva al desarrollo de nuevas vías que escapan de la propia categoría documental al inmiscuirse en la ficción ${ }^{7}$. También es interesante señalar cómo la transmedialización, tal y como indican Domingo SánchezMesa y Jan Baetens, «es el mecanismo o proceso que "adapta" una obra que existe en un medio determinado a otro medio» (2017: 9). Es por ello que la categoría «transmedia» se debe aplicar en este tipo de proyectos documentales únicamente a aquellas obras que se expanden fuera del medio audiovisual, porque de no ser así se permanecería en el mismo medio y no sería totalmente pertinente esta etiqueta, es decir, tal y como afirman estos autores, si «bien todas las transmedializaciones son adaptaciones, no todas las adaptaciones son transmedializaciones puesto que es perfectamente posible adaptar una obra manteniéndose en un mismo medio» (ibíd.).

Dentro de la tipología de documentales en los proyectos transmedia encontramos una amplia variedad que de alguna manera está provocando una reconceptualización de lo que entendemos por género documental, resultado de la alteración de las condiciones tradicionales tanto de creación como de recepción. Tal es la diversidad de los documentales transmedia que, como dice Anxo Abuín,

\footnotetext{
${ }^{7}$ Este proceso, absolutamente natural, dificulta la posibilidad de hablar de documentales transmedia, por lo que, y de una manera ortodoxa pero también limitadora, deberíamos hablar de proyectos transmedia factuales, ya que la factualidad del hecho o los hechos sobre los que se sustentan los diferentes materiales se considera indispensable para el carácter unitario que deben tener estos productos.
} 
[...] desafían incluso clasificaciones como la de Bill Nichols [...]. Por su estética se acercan al modo participativo (uso de entrevistas) y al performativo (deseo de comprometer al público y uso de formas expresivas como el recitado de poemas para crear una intensidad emocional y casi poética), pero su engagement va más allá: la textualidad es aquí completamente abierta e imprevisible, no tiene límites y se presenta como un work-in-progress en el que la clausura del sentido nunca se da por garantizada (Abuín, 2017: 117).

Sin lugar a dudas la clasificación de Nichols se muestra insuficiente cuando nos hallamos en un nuevo paradigma audiovisual dentro de la comunicación digital, donde la virtualidad, la inmediatez o lo interactivo se constituyen en muestras claras de la nueva deriva de este medio. Un ejemplo de esto lo podrían constituir los documentales que usan la realidad virtual (VR) como vehículo para sus producciones, ya que estas suponen el grado máximo de simulación e interactividad. Esto además problematiza en torno a cuestiones como la figura del narrador, ya que la focalización aquí no es unívoca, sino múltiple al no existir un único encuadre. Para esbozar los problemas que introduce esto vamos a partir de la definición de Ramón Carmona sobre el encuadre:

El encuadre testimonia la puesta en relación entre un observador y los objetos figurativos que aparecen en la pantalla [...], introduciendo la discontinuidad, la fragmentación y la posibilidad de recomponer el orden del espacio del «mundo natural» en un orden antinatural, sólo predicable del discurso fílmico (1996: 99).

Nos resulta interesante esta definición porque el encuadre suele ser usado en algunos géneros cinematográficos como marca de enunciación, evidenciando así la figura del narrador. Piénsese por ejemplo en el caso del cine de terror con el personaje del asesino, cuando se usa el plano subjetivo para mostrar el peligro que se cierne sobre los protagonistas. El encuadre introduce una tensión narrativa puesto que la focalización en ese momento se corresponde con la del propio personaje. Pero si pensamos en el documental, son numerosos los casos en los que se puede dar esta misma casuística. Guest (2010), de José Luis Guerín, se constituye en un buen ejemplo, un documental autoficcional en la que el director barcelonés retrata su día a día recorriendo festivales de cine por todo el mundo. Los encuadres que vemos son reproducciones exactas de lo que Guerín está observando en ese momento a través de su cámara.

En la definición de Carmona también nos resulta interesante la referencia al encuadre como forma de descomposición del mundo natural. La fragmentación mediante la planificación cinematográfica hace que la realidad se vea parcelada y que posteriormente, durante el visionado y mediante la sintaxis del montaje, el espacio pueda ser reconstruido en la mente del espectador. Precisamente es esa visión fragmentada la que es disuelta en el documental VR. Como resultado no es posible hablar del fuera de campo en todas sus acepciones tradicionales: lo que permanece fuera del encuadre, lo que queda por detrás de la cámara y lo que se esconde detrás de los elementos de la escenografía. Evidentemente siempre va a existir un fuera de campo, pero este va a ser ahora múltiple, ya que será el propio espectador el que selecciona el encuadre que desea ver. Así mismo no existe un fuera de campo detrás de la cámara, ya que la visión en $360^{\circ}$ provoca que todo el espacio circundante a la cámara sea visible. Sólo encontraríamos el fuera de campo detrás de los objetos, ya que los primeros intentos de aplicar la realidad virtual al documental no han llevado asociada una interactividad que permita romper con esto. Se produce así con el VR una reconsideración de la espacialidad, ya que es 
un espacio habitado por el espectador, algo que le acercará al mundo de los videojuegos ${ }^{8}$, donde el espectador ahora ya no se proyecta en el espacio, ahora cree estar en él.

Se rompe además con uno de los modos narrativos por excelencia, el pasado, para crear un presente paradójico, puesto que el pretérito ya está preinscrito en la banda sonora y visual ${ }^{9}$. El espectador, al seleccionar el fragmento de «mundo» que quiere ver, realiza una acción en directo, con lo cual a pesar de estar viendo una imagen captada tiempo atrás, fragmenta la realidad captada creyendo tener una experiencia en «presente». Esta sensación de presente sería una de las consecuencias narratológicas derivadas de la interactividad de estos nuevos medios, otro aspecto que hace que el documental se aproxime al mundo del videojuego, donde existe una aparente incompatibilidad con el pasado (Sánchez-Mesa, 2011: 116).

Encontramos así una amplia variedad de problemas teóricos a la hora de abordar estas nuevas formas audiovisuales. Pero debemos remarcar la importancia de la conexión del discurso documental con la realidad, ya que es condición indispensable para que se pueda hablar de documental. No sólo debe ser verosímil el mundo que es narrado como fruto de su contrastabilidad, sino que además el narrador se debe constituir en una figura en la que el espectador pueda confiar para que esa experiencia documental sea plena. Si no, la ficción invadiría la propuesta perjudicando la consecución del objetivo primigenio de este tipo de obras, la persuasión a través de la realidad que se narra. Sin esto, lo transmedial se vería comprometido, y se constituiría en otro tipo de documental: «Si el documental interactivo encontró en la web un espacio privilegiado de expresión, el documental transmedia va más allá y lleva sus contenidos a otros medios y plataformas, buscando siempre la complicidad de los prosumidores» (Scolari, 2012). El espectador, por tanto debe ocupar por tanto un lugar esencial en estas propuestas, convirtiéndoles explícitamente incluso en narratarios y lograr así una mayor adhesión a la propuesta transmedial.

\section{Análisis de casos: La Primavera Rosa y Cromosoma cinco.}

Un caso claro de cómo el documental transmedia sufre mutaciones dependiendo del tipo de plataforma y medio lo podemos ver en La Primavera Rosa (Mario de la Torre, 2013-) ${ }^{10}$, un proyecto de activismo que toma el documental como punto de partida a la hora de establecer su peculiar narrativa relatando la violación de derechos contra la comunidad LGBTI en el mundo. En la primera etapa se realizó una pieza audiovisual de dieciocho minutos y destinada a eventos cinematográficos -festivales, muestras, cinefórums...- que describía los problemas de gays y bisexuales en Túnez a

\footnotetext{
${ }^{8}$ A pesar de esto, los videojuegos marcan aquí su principal diferencia con el mundo del documental que es mostrado mediante la realidad virtual. Mientras que en el primer caso los espacios son explorables, permitiendo una interacción cada vez mayor, la realidad virtual documental no permite más que realizar un giro de $360^{\circ}$ sobre el propio eje, sin posibilidad de interactuar con los elementos del escenario. A pesar de esto, cada vez son mayores los intentos de romper con estas limitaciones aproximando la experiencia documental a la del videojuego al potenciar la interactividad.

${ }^{9}$ Decimos únicamente visual porque si bien los $360^{\circ}$ de este tipo de productos audiovisuales permiten ver todo lo que sucede alrededor de la cámara desde el punto de vista de la lente, eligiendo el espectador el fragmento de la realidad que desea ver, en cambio el sonido no está teniendo el mismo desarrollo para permitir una auricularización plena.

${ }^{10} \mathrm{http}$ ://www.laprimaverarosa.com/ (última consulta, 10-7-2017).
} 
pesar de los avances que esperaban en derechos en cuanto a orientación e identidad sexual tras la Primavera Árabe. Es sintomático que esta pieza fuera estrenada en competición dentro del festival Documenta Madrid. El destinatario es aquí un espectador interesado en el cine documental que decide visitar una cita cinematográfica como esta para descubrir los nuevos trabajos en este género. Teniendo en cuenta que su objetivo es denunciar la realidad del colectivo, «se ha ido expandiendo desde lo puramente fílmico [...] hasta otros ámbitos "ancilares"》 (Abuín, 2017: 112). A este respecto es innovador el uso del documentarybook (imagen 1), un formato desarrollado por el equipo del proyecto que toma el documental como punto de partida añadiéndole contenidos adicionales. En la primera parte en Túnez se añaden videos que ayudan a comple-

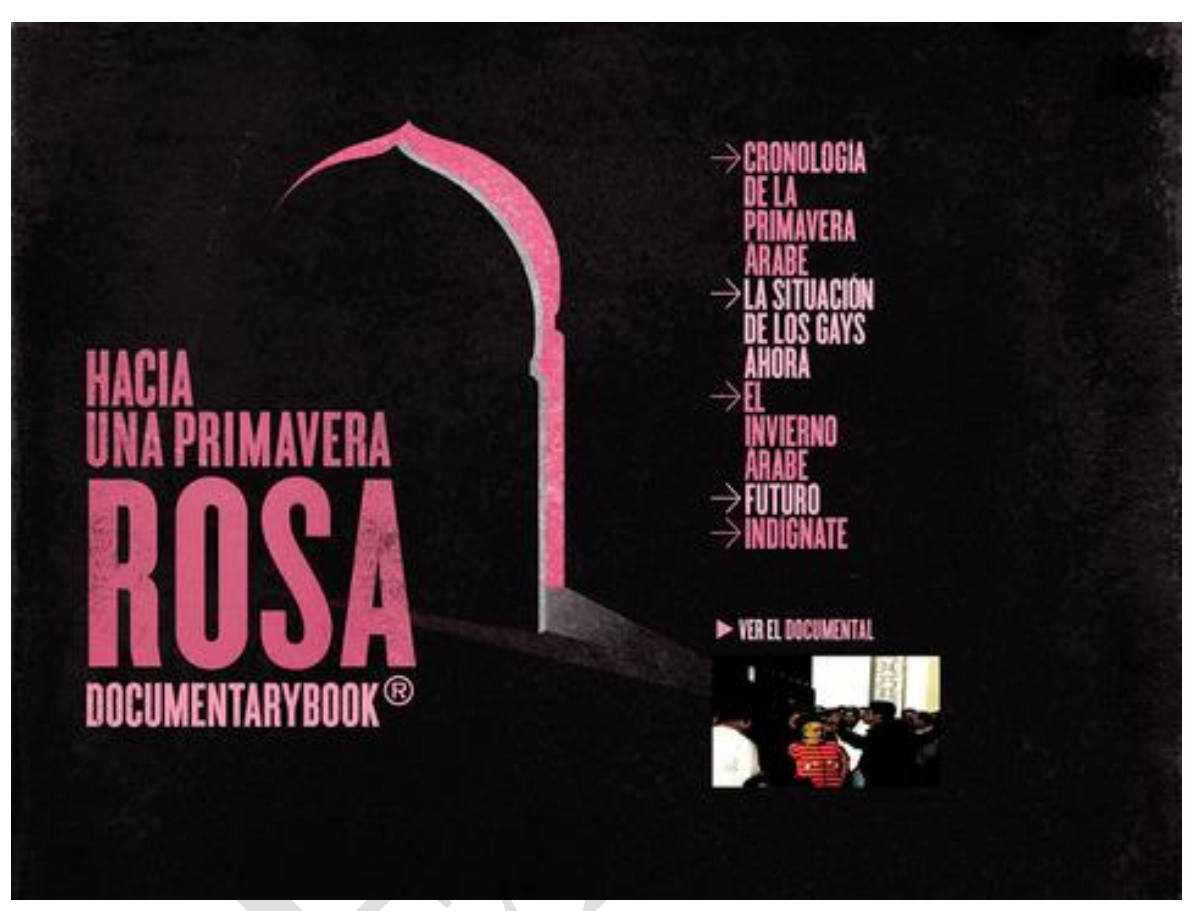

Imagen 1. Página principal del documentarybook Hacia una primavera rosa mentar la visión sobre la persecución que sufre la comunidad de gays y lesbianas tunecinos. Es interesante mencionar esta plataforma, descargable gratuitamente desde Apple Store, porque esta

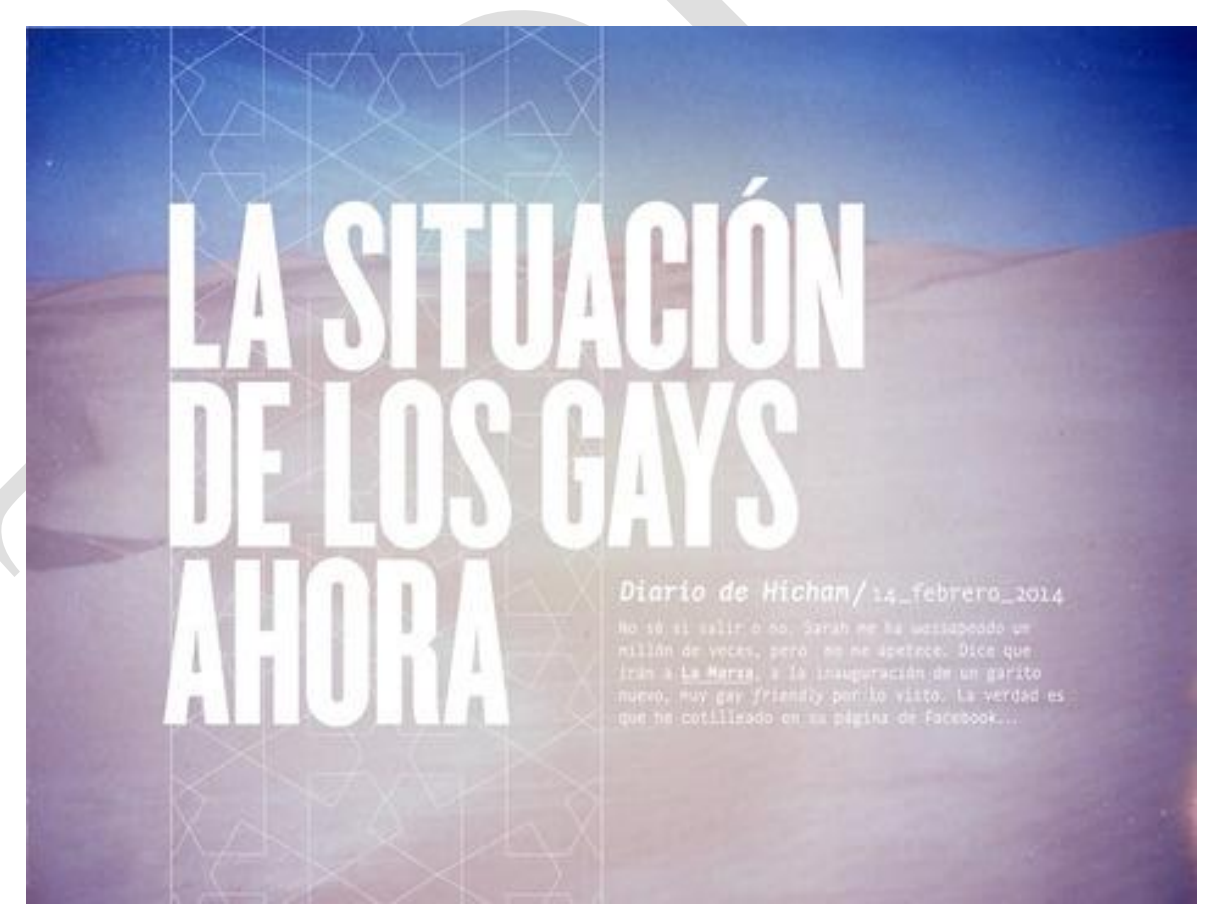

Imagen 2. Portada del «Diario de Hicham», en el documentarybook Hacia una primavera rosa. innovación, a un nivel tecnológico, atrajo la atención de los medios, apareciendo en programas televisivos especializados como Cámara Abierta 2.0., logrando así una mayor repercusión de su mensaje de denuncia. También cabría mencionar algunos contenidos añadidos que exceden del web-doc. Es el caso de «El diario de Hicham» (imagen 2), donde se relata el día a día de un joven tunecino gay. Evidentemente el propio género diarístico 
lleva asociada una narración de corte homodiegético, con lo cual la figura del narrador es clara. Y el narratario no deja de ser él mismo, para el que escribe sus incidencias diarias, aunque el acceso al diario, pleno de hiperenlaces que permiten ampliar la realidad narrada, permite la lectura a cualquier usuario. Con el ofrecimiento al espectador de la posibilidad de introducirse en la intimidad de un personaje LGBTI en el mundo árabe se potencia además la capacidad persuasiva del proyecto.

Más adelante, y durante la filmación en México de la tercera etapa de La Primavera Rosa, se rodó una sesión fotográfica de los artistas Gabriel Pineda y Gerardo Estrada. En ella aparece Alberta

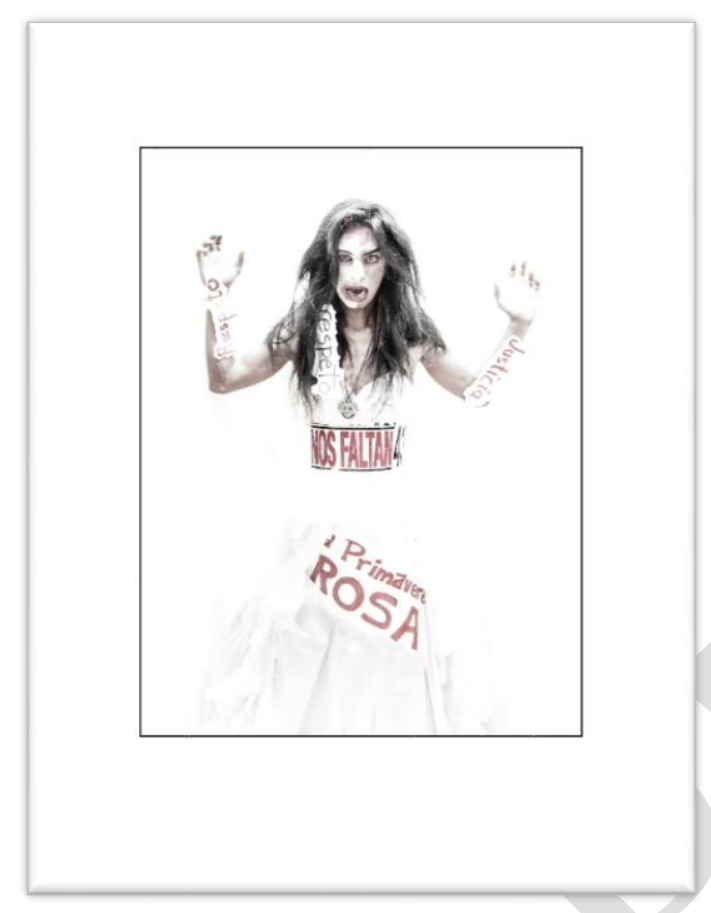

Imagen 3. La Primavera Rosa, por Gabriel Pineda y Gerardo Estrada
Cánada, álter ego del artista multidisciplinar José Alberto Patiño, siendo retratada por la pareja mexicana. La fotografía resultante de la sesión, titulada $L a$ Primavera Rosa, pasaría a ser la imagen del proyecto global. Además, se convertiría en una de las piezas centrales en diferentes exposiciones llevadas a cabo en torno a su serie fotográfica Seres de luz, en la que retratan la diversidad sexual de su país con el fin de denunciar la violación sistemática de derechos humanos. En este caso, asumiendo la fotografía como arte narrativo - asunto este dotado de una complejidad teórica de la que no nos ocuparemos en esta ocasión-, vemos un grito de auxilio y de dolor (imagen 3 ) donde la figura del narrador se correspondería con los propios fotógrafos, inscritos en la banda audiovisual del documental y participantes plenos en la diégesis fílmica.

Es interesante comprobar que, aprovechando la presentación del documental en la $18 .^{a}$ Semana del Cortometraje de la Comunidad Madrid, con la presencia de Alberta Cánada, esta montara y representara en la madrileña Sala Mínima el espectáculo teatral autoficcional Vestida y Alborotada, en la que parte de la casualidad de entrar en el proyecto La Primavera Rosa para pasar a realizar un recorrido por la homofobia y la represión sexual en México. El artista, acostumbrado a realizar vestidos con materiales reciclados como el papel o el plástico - labor que le ha reportado incluso premios de artes plásticas-, utilizó impresiones de la fotografía del proyecto para realizar uno de los trajes que saca a escena, produciéndose un diálogo muy interesante entre diferentes medios.

Si esto supone una expansión del documental hacia otros ámbitos como el teatro, no hay que dejar de señalar lo acontecido en la exposición en el centro cultural Casa de Vacas con el nombre Make America Dystopian Again, con obras de Yoko Ono o Andy Warhol. En ella el comisario, Pablo Peinado, creó una instalación titulada La Primavera Rosa (imagen 4), en la que utilizó la fotografía de La Primavera Rosa y una serie de carteles que José Alberto Patiño usó durante la representación de Vestida y Alborotada y donde aparecían diferentes formas de llamar a los miembros de la comunidad 
LGBTI en México. Se produce así una muestra de crowdsourcing y de expansión del proyecto ${ }^{11} L a$ Primavera Rosa y sin perder su razón de ser, convertirse en una herramienta de denuncia social ${ }^{12}$.

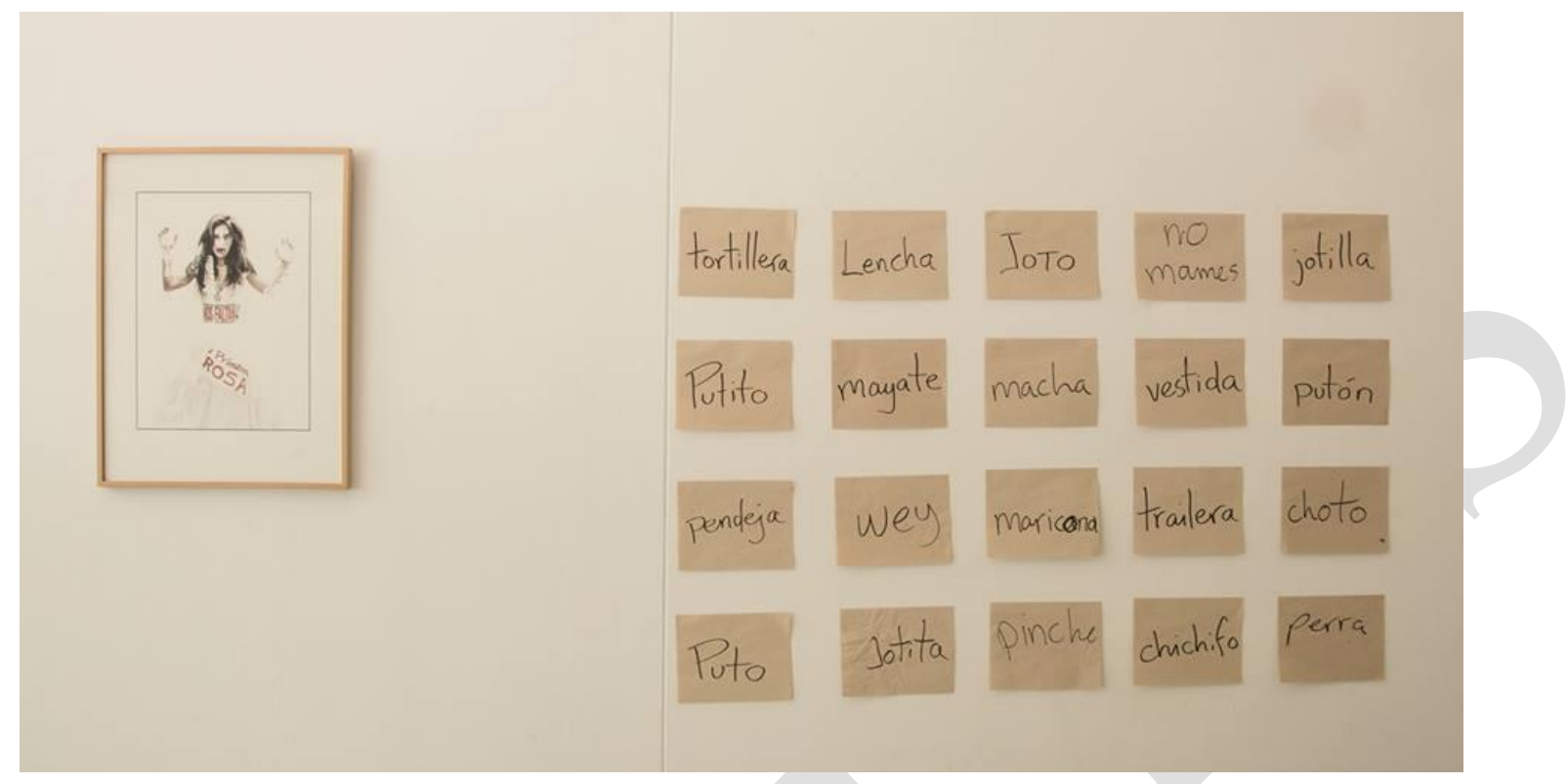

Imagen 4. La Primavera Rosa, de Pablo Peinado.

Si el proyecto mencionado parte de una iniciativa privada y es llevado a cabo con producción independiente, Cromosoma cinco (2013), por su parte, es un proyecto desarrollado por Lisa Pram y María Ripoll dentro del Lab de RTVE ${ }^{13}$. En este proyecto se intenta retratar el día a día de Pram con su hija Andrea, aquejada del síndrome del maullido del gato, una alteración en el cromosoma quinto que ocasiona retrasos en su desarrollo. Aunque pueda entenderse que se trata de un simple web-doc, lo interesante es tomar como punto de partida material las fotografías que Lisa Pram tomó de ella misma y de su hija, y como storyline la historia personal de aceptación y amor hacia su hija. Hay que mencionar que Pram es una fotógrafa de prestigio, responsable de editoriales en revistas de tendencias, así como autora de fotografías para importantes marcas publicitarias. Esta vocación artística le llevó a que ya durante el embarazo de su primogénita comenzara a tomar fotografías del proceso, con el objetivo de documentar los nueve meses de gestación. Es interesante ver cómo esas fotografías (imagen 5), visibles a través del documental en la web, la página personal de la fotógrafa así como algunas exposiciones, son en realidad autorretratos en su intimidad. Funcionan de este modo casi a modo de diario, con lo que en un análisis narratológico podríamos decir que en esta narración

\footnotetext{
${ }^{11}$ El proyecto consta, entre otros, de tres documentarybooks, cuatro documentales para su proyección en cines y su retransmisión por internet, una monografía, el uso activo de redes sociales, un documental en realidad virtual y cuatro web-docs. ${ }^{12}$ Es muy interesante contemplar cómo se produce la proyección del documental en otros medios, como pueden ser las artes plásticas con la instalación de Pablo Peinado. Viene así a apoyar las declaraciones de Domingo Sánchez-Mesa y Jan Baetens acerca de la refutación de la inmaterialidad de los contenidos: «En primer lugar porque no compartimos la idea del contenido como una entidad inmaterial. Aunque no todas las franquicias crossmediales o los proyectos estrictamente de narrativa transmedial desplazan la historia a un lugar secundario, es evidente la tendencia creciente a priorizar la construcción de los mundos narrativos o storyworlds a partir de la llamada mothership o conjunto de contenidos (personajes, espacios, tiempos, valores) que conforman ese mundo "previo" a las historias que se desarrollan en él» (2017: 11).

${ }^{13}$ http://www.rtve.es/cromosomacinco/ (última consulta, 10-7-2017).
} 
autodiegética la instancia narradora coincide con Lisa Pram, mientras que el narratario quedaría implícito, correspondiéndose en realidad con ella misma y su marido, para quienes efectúa las fotos.

Cuando nace Andrea y descubren su afección, Pram decide comenzar a crear un libro en formato papel, de título Little Black Book. En él recoge sus sensaciones, sentimientos e ideas durante su día a día. Entre otras cosas, la pesadumbre que le

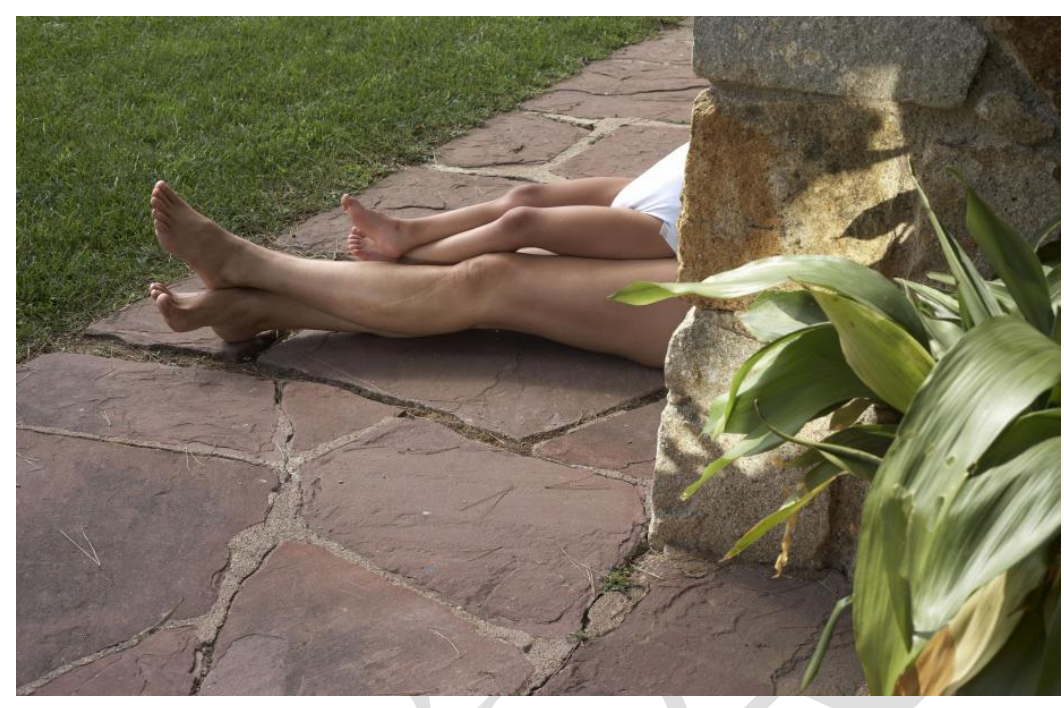

Imagen 5. Fotografía de Lisa Pram con su hija. ocasiona el tener que asumir la situación de su hija. Esta obra se trata de un soporte texto-visual donde, junto a las fotografías e ilustraciones de la propia autora, aparecen poemas y textos más o menos narrativos (imagen 6). Entre los materiales empleados destacan las fotografías que realizó durante su embarazo, pero aquí con una nueva significación. Si en un comienzo las fotos denotaban ilusión por

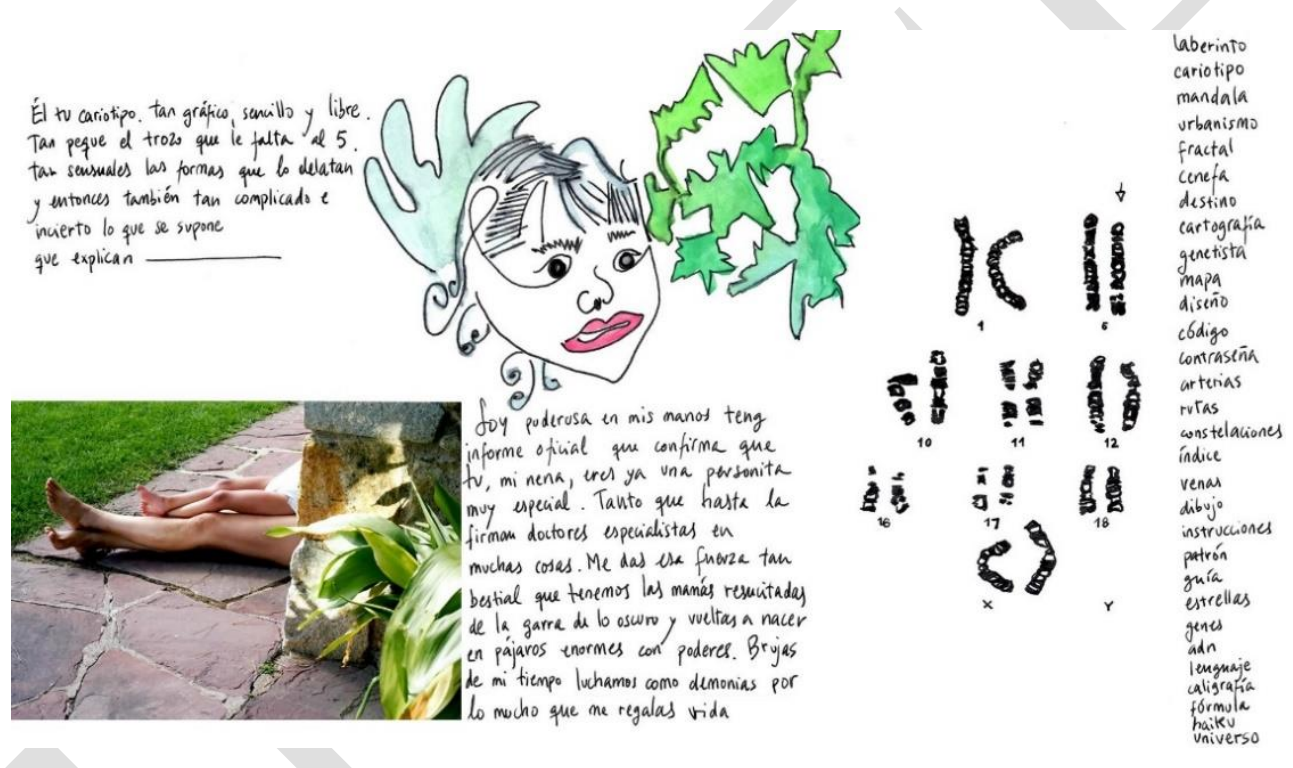

Imagen 6. Little Black Book, por Lisa Pram. lo que habría de llegar tras el parto y por un incipiente amor maternal durante la gestación, al conocer el diagnóstico estas fotografías se usan para transmitir la resignación que siente ante la situación sobrevenida. El texto, estructurado en orden cronológico a medida que iban sucediendo los hechos na-

rrados, arranca así: «Esta historia empieza en el preciso momento en que decides nacer. Mucho antes de término. Mi lado de la cama inundado de viscoso líquido oxígeno de mi bebé». Aquí la narradora sigue siendo Pram, pero las narratarias pasan a ser sus dos hijas, tanto Andrea - a la cual idealiza como una narrataria ideal al presuponerle capacidades cognitivas para el entendimiento del librocomo su hija pequeña Billie, que nacería más tarde.

Un encuentro fortuito hizo que la directora de cine María Ripoll descubriera la historia de Pram y Andrea, así como la belleza del libro. Ripoll animó a Pram a realizar una obra audiovisual, dando 
como resultado un documental interactivo accesible a través de la web de RTVE. Este documental, como es propio de los web-docs, se puede visualizar de diferentes maneras. Está dividido en nueve capítulos, haciendo referencia a los nueves meses de embarazo y de esta manera subrayando el subtexto sobre la maternidad que enmarca el proyecto. Accediendo a los títulos de los capítulos se accede además a las diferentes partes del documental, algo que también se puede realizar a través del Little Black Book que aparece digitalizado en la interfaz principal, posibilitándose así el visionado del documental según el orden que se desee, bien desde el texto de los títulos de los capítulos o bien desde las imágenes del libro.

Siguiendo con las teorías de Gaudreault y Jost (2001), hablaríamos en este momento de la presencia de un meganarrador que encubre toda la propuesta. Pero si analizamos en profundidad el documental se puede descubrir ciertas prácticas que desvían la simple visión de la obra como expositiva. Ello queda muy claro en el código visual empleado. Durante parte importante del metraje se puede ver cómo las directoras usan una lente que desenfoca la realidad al difuminar los bordes del encuadre. El objetivo es mostrar una imagen distorsionada del mundo, intentando hacerla coincidir con la visión de Andrea. Se trataría de la búsqueda de una focalización interna con el objetivo de buscar la identificación del espectador con la realidad que le es narrada.

Otro caso interesante de ruptura se encuentra hacia el minuto cuarenta y cinco cuando vemos a

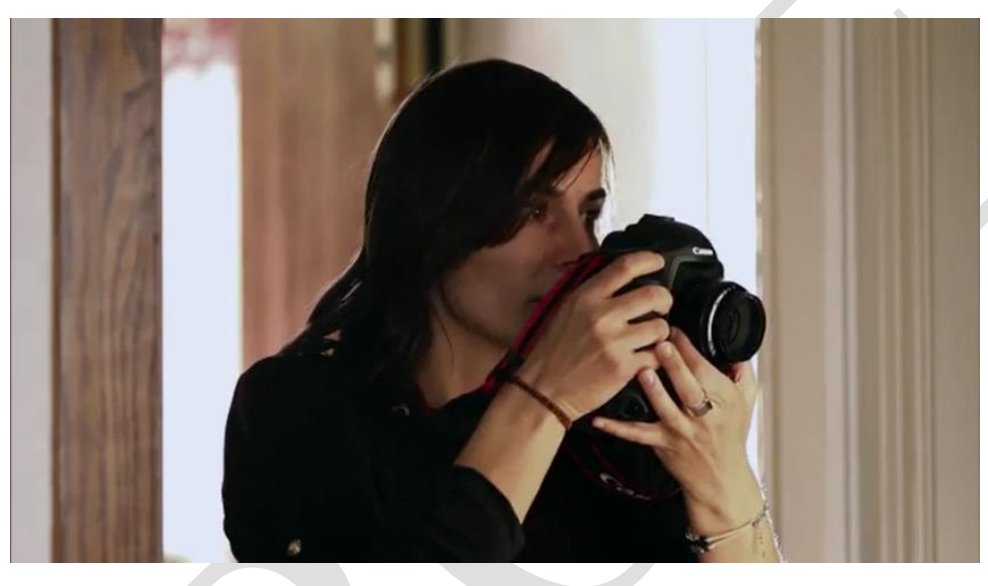

Imagen 7. Fotograma del documental Cromosomq cinco. Lisa Pram con su cámara (imagen 7). Si hasta el momento la habíamos visto de una forma heterodiegética, en este momento comenzamos a ver únicamente las imágenes que está tomando. Se produce así una metalepsis, puesto que de aparecer entrevistada o en escenas de corte observacional pasa a focalizar el punto de vista narrativo, pasándose a una narración autodiegética, entendiéndose esta como aquella narración en la que el narrador de la historia relata sus propias experiencias siendo al mismo tiempo persona principal de esa obra (Genette, 1972: 51).

Ahora, la otra cuestión pendiente de evaluar sería cuál es la figura con la que se corresponde el narratario. Si atendemos al web-doc, vemos cómo van apareciendo enlaces web que remiten a asociaciones o colectivos que tratan sobre esta u otras enfermedades catalogadas como raras. Además, existen vínculos que llevan a los perfiles en redes sociales del proyecto, como Facebook o Twitter. Uno de los motores del proyecto es concienciar sobre la necesidad de reconocimiento y apoyo a todas las personas afectadas de enfermedades raras, con lo cual se buscaba siempre el máximo impacto posible. Estaríamos diciendo por tanto que el documental tiene como destinatario el público en general, al que se trata de conmover para que se involucre y actúe en consecuencia con lo narrado. Se trataría 
de un ejemplo de expansión del mundo transmedia del documental, el hecho de que se pase de la recepción pasiva de lo narrado a la movilización a la acción por parte de los espectadores, que se convertirán de esta forma en auténticos prosumidores. Enlaces a webs como Change.org son sólo muestras de cómo este proyecto busca extenderse desde la realidad al resto de realidades sociales, un trasvase desde el mundo factual representado en el proyecto documental al mundo real exterior. El proyecto, a este respecto, ejemplifica a la perfección la visión sobre el transmedia storytelling de Robert Pratten, en concreto en relación a la búsqueda de las motivaciones intrínsecas de autorrealización en el público (2015: 87), es decir, «[to] focus on an emotional, participatory experience for the audience» (ibíd.: 3) para que dicha audiencia provoque cambios a su alrededor. El célebre consultor británico tiene claro que «stories matter, that those stories need to be told to the right people at the right time and most importantly that projects should offer a pathway to success» (ibid.: 203) y, de este modo, proyectarse intentando cambiar vidas personales y solventar problemas sociales.

Se constituyen así estos dos documentales, donde se produce un trasvase de las figuras de narrador y narratario a medida que se cambia de medio, en muestra de narrativas transmedia que exceden el ámbito de los mundos ficcionales a los que hacía mención Jenkins. En sintonía con Sánchez-Mesa y Jan Baetens, por tanto,

[...] no deberíamos descuidar que la articulación formal y discursiva de los contenidos de una obra comportan una evaluación del mundo a través de los personajes y sus lenguajes sociales, que quedan fuera de foco cuando el ethos (importante, hay que reconocerlo, para el discurso de la producción del Transmedia Storytelling) se considera al margen de los distintos modos de enunciación propios de cada medio. Hablamos, no obstante, de tendencias dominantes, pues es evidente que no faltan proyectos que sí tratan de explotar esta dimensión discursiva de las narrativas transmediales, eso sí, en producciones habitualmente al margen de la gran industria, o dentro de los circuitos independientes (2017: 12).

El documental transmedia se configura así como una tendencia en auge que requiere de nuevas revisiones teóricas para lograr la máxima explotación de su potencial creativo, ya sea desde los New Media Studies, la literatura comparada o la narratología. Entre los temas sobre los que cabría reflexionar, urge la consideración de la necesidad o no de la ficción como elemento definitorio de lo transmedia, puesto que la proliferación cada vez mayor de elementos factuales en este tipo de narraciones está demostrando que existe un amplio campo por explorar. En una sociedad donde la idea del simulacro de Baudrillard está más presente que nunca, es preciso que se pueda trabajar ampliamente con lo real, aunque se parta desde un nuevo marco ontológico, y en esta labor las narrativas transmedia se muestran más enriquecedoras que nunca.

\section{Bibliografía}

Abuín, A. (2017): «Táctica frente a estrategia: transmedialidad y activismo en Ciutat Morta», Tropelías. Revista de Teoría de la Literatura y Literatura Comparada, 27, pp. 110-119; en https://papiro.unizar.es/ojs/index.php/tropelias/article/view/1543 (última consulta, 10-7-2017).

BURCH, N. (1999): El tragaluz del infinito: contribución a la genealogía del lenguaje cinematográfico. Trad. Francisco Llinas. Madrid, Cátedra. 
Carmona, R. (1996): Cómo se comenta un texto fílmico. Madrid, Cátedra.

Gaudreault, A. - Jost, F. (2001): El relato cinematográfico. Trad. Nuria Pujol. Barcelona, Paidós.

GeneTte, G. (1972): Figures III. París, Seuil.

GIFREU-CAstells, A. (2016): «El ámbito de la no ficción interactiva y transmedia. Aproximación a cuatro formas de expresión narrativa», Opción: revista de ciencias humanas y sociales, especial 9, pp. 871-891.

MetZ, C. (1970): «El decir y lo dicho en el cine: ¿hacia una decadencia de un cierto verosímil?», en R. BARTHES et al., Lo verosímil. Trad. Beatriz Dorriots. Buenos Aires, Tiempo Contemporáneo, pp. 17-30.

Nichols, B. (2013): Introducción al documental. Trad. Miguel Bustos García. México, UNAM.

PRATTEN, R. (2015): Getting Started in Transmedia Storytelling. A practical Guide for Beginners, en http://www.tstoryteller.com/getting-started-in-transmedia-storytelling (última consulta, 10-72017).

RENÓ, D. (2014): «Diversidad de formatos para documentales transmedia», en Actas del VI Congreso Internacional Latina de Comunicación Social, Tenerife, Universidad de La Laguna, en http://www.revistalatinacs.org/14SLCS/2014_actas/141_Reno.pdf (última consulta, 10-6-2017).

Ricoeur, P. (1987): Tiempo y narración II: configuración del tiempo en el relato de ficción. Trad. Agustín Neira. Madrid, Cristiandad.

ROSENDO SÁNCHEZ, N. (2016): «Mundos transmediales: revisión conceptual y perspectivas teóricas del arte de crear mundos», Icono 14, 1/14, pp. 49-70; en http://www.icono14.net/ojs/index.php/ icono14/article/view/930/541 (última consulta, 10-7-2017).

RYAN, M. L. (2014): «Story/Worlds/Media. Tuning the Instruments of a Media-Conscious Narratology», en M. L. RYAn y J. N. ThON, eds., Storyworlds across Media. Toward a MediaConscious Narratology. Lincoln, University of Nebraska Press, pp. 25-49.

- (2016): «Transmedia narratology and transmedia storytelling», Artnodes: Journal on Art, Science and Technology, 18, pp. 1-10; en https://artnodes.uoc.edu/articles/abstract/10.7238/ a.v0i18.3049/ (última consulta, 10-7-2017).

SÁNCHEZ-MESA, D. (2011): «Literatura aumentada. Intermedialidad / Transmedialidad o el Viaje de Alicia a través de las pantallas», en S. MonTESA, ed., Literatura e Internet. Nuevos Textos, Nuevos Lectores. Málaga, Publicaciones del Congreso de Literatura Española Contemporánea, pp. 109-129.

SÁNCHEZ-MESA, D. - BAETENS, J. (2017): «La literatura en expansión. Intermedialidad y transmedialidad en el cruce entre la literatura comparada, los estudios culturales y los new media studies», Tropelías. Revista de Teoría de la Literatura y Literatura Comparada, 27, pp. 6-27; en https://papiro.unizar.es/ojs/index.php/tropelias/article/view/1536 (última consulta, 10-7-2017).

SCOLARI, C. S. (2012): «Más allá de la ficción: el documental transmedia», en https:// hipermediaciones.com/2012/05/09/mas-alla-de-la-ficcion-el-documental-transmedia/ (última consulta, 10-07-2017). 
TORRE EsPinOSA, M. DE LA (2015): «Cines del yo: el documental autoficcional contemporáneo español», Bulletin of Hispanic Studies, 92/5, pp. 567-582.

VANOYe, F. (1998): Récit écrit, récit filmique. Paris, Nathan.

WeInRICHTER, A. (2004): Desvíos de lo real. El cine de no ficción. Madrid, T\&B.

ŽIŽEK, S. (2005): Bienvenidos al desierto de lo real. Trad. Cristina Vega Solís. Madrid, Akal. 